\title{
Article \\ Prognostic Value of Sarcopenia in Metastatic Colorectal Cancer Patients Treated with Trifluridine/Tipiracil
}

\author{
Mateusz Malik 1,*(D), Maciej Michalak ${ }^{2,3}$, Barbara Radecka 4,5 ${ }^{1}$, Marek Gełej 4,5, Aleksandra Jackowska ${ }^{6}$, \\ Emilia Filipczyk-Cisarż ${ }^{1}$, Katarzyna Hetman ${ }^{7}$, Małgorzata Foszczyńska-Kłoda ${ }^{7}$, Beata Kania-Zembaczyńska ${ }^{8}$, \\ Danuta Mańka ${ }^{8}$, Marlena Orlikowska ${ }^{9}$, Hanna Rogowska-Droś ${ }^{3}$ and Lubomir Bodnar ${ }^{6}$ D
}

Citation: Malik, M.; Michalak, M.; Radecka, B.; Gełej, M.; Jackowska, A.; Filipczyk-Cisarż, E.; Hetman, K.; Foszczyńska-Kłoda, M.;

Kania-Zembaczyńska, B.; Mańka, D.; et al. Prognostic Value of Sarcopenia in Metastatic Colorectal Cancer Patients Treated with Trifluridine/Tipiracil. J. Clin. Med. 2021, 10, 5107. https://doi.org/ $10.3390 /$ jcm 10215107

Academic Editor: Masahiro Tajika

Received: 25 August 2021

Accepted: 28 October 2021

Published: 30 October 2021

Publisher's Note: MDPI stays neutral with regard to jurisdictional claims in published maps and institutional affiliations.

Copyright: (C) 2021 by the authors Licensee MDPI, Basel, Switzerland. This article is an open access article distributed under the terms and conditions of the Creative Commons Attribution (CC BY) license (https:// creativecommons.org/licenses/by/ $4.0 /)$.
1 Lower Silesian Oncology Centre, Clinical Oncology Department, Plac Ludwika Hirszfelda 12, 53-413 Wroclaw, Poland; cisarz.emilia@dco.com.pl

2 Department of Radiology, Faculty of Medicine, University of Warmia and Mazury in Olsztyn, Aleja Warszawska 30, 11-082 Olsztyn, Poland; macrad1@wp.pl

3 Diagnostic Imaging Department, MSWiA Hospital, Warmia and Mazury Oncology Centre, Aleja Wojska Polskiego 37, 10-228 Olsztyn, Poland; hanrog@mp.pl

4 Department of Oncology, Institute of Medical Sciences, University of Opole, Oleska 48, 45-052 Opole, Poland; brad@onkologia.opole.pl (B.R.); mgelej@gmail.com (M.G.)

5 Tadeusz Koszarowski Cancer Center in Opole, Department of Clinical Oncology, Katowicka 66a, 45-061 Opole, Poland

6 Oncology and Immunooncology Clinic, MSWiA Hospital, Warmia and Mazury Oncology Centre, Aleja Wojska Polskiego 37, 10-228 Olsztyn, Poland; purf_1@wp.pl (A.J.); lubomirbodnar.lb@gmail.com (L.B.)

7 West Pomeranian Oncology Center in Szczecin, Department of Clinical Oncology, Strzalowska 22, 71-730 Szczecin, Poland; khetman@onkologia.szczecin.pl (K.H.); mfoszczynska@onkologia.szczecin.pl (M.F.-K.)

8 Beskid Oncology Centre in Bielsko-Biala, Department of Oncology and Oncohematology, Wyzwolenia 18, 43-300 Bielsko-Biala, Poland; bzembaczynska@gmail.com (B.K.-Z.); danuta.manka@gmail.com (D.M.)

9 Kociewie Health Centre, Oncology Department, Doktora Jozefa Balewskiego 1, 83-200 Starogard Gdanski, Poland; orlik-marlena@o2.pl

* Correspondence: mateusz.w.malik@gmail.com; Tel.: +48-880343400

Abstract: Sarcopenia is common in metastatic colorectal cancer (mCRC), increases the risk of treatment-related toxicity and reduces survival. Trifluridine/tipiracil (TT) chemotherapy significantly improved survival in refractory mCRC patients, but the prognostic and predictive role of pretherapeutic sarcopenia and variation in the skeletal muscle index (SMI) during this treatment has not been investigated so far. In this retrospective, observational study, clinical data on mCRC patients treated with TT at six cancer centres in Poland were collected. Computed tomography (CT) scans acquired at the time of initiation of TT (CT1) and on the first restaging (CT2), were evaluated. SMI was assessed based on the skeletal muscle area (SMA) at the level of the third lumbar vertebra. Progression-free survival (PFS) and overall survival (OS) were calculated from the treatment start. Neither initial sarcopenia nor $\geq 5 \%$ skeletal mass loss (SML) between CT1 and CT2 had a significant effect on PFS in treated patients ( $p=0.5526$ and $p=0.1092$, respectively). In the multivariate analysis, reduced OS was found in patients with $\geq 5 \%$ SML (HR: 2.03 (1.11-3.72), $p=0.0039$ ). We describe the prognostic role of sarcopenia beyond second line treatment and analyze other factors, such as performance status, tumor histological differentiation or carcinoembryonic antigen level that could predict TT treatment response.

Keywords: sarcopenia; metastatic colorectal cancer; cancer cachexia; trifluridine/tipiracil

\section{Introduction}

Colorectal cancer (CRC) is of considerable epidemiological importance worldwide, as the third most common malignant disease ( 1.85 million new cases annually; $10.2 \%$ of all malignancies). CRC is responsible for approximately $8.9 \%$ of cancer-related deaths, with an over 30\% increase in the last 15 years [1]. Despite this upward trend in global mortality, 
5-year survival in Polish patients with CRC has improved over the past two decades: from 43.3 to $47.6 \%$ in men, and from 44.1 to $49.1 \%$ in women [2].

Sarcopenia is defined as a loss of skeletal muscle mass associated with reduced muscle strength and impaired physical function. Sarcopenia as a component of cancer cachexia is a complex condition involving nutritional deficiency, chronic inflammation, metabolic imbalance towards hypercatabolism and lower physical activity followed by poor performance status (PS), an increased risk of treatment-related toxicity and reduced survival [3].

Colorectal carcinoma, especially advanced, is itself considered a risk factor for cachexia and sarcopenia. Sarcopenia, both primary (aging-related) and secondary (caused by pathogenic mechanisms), is frequent in patients with CRC, ranging between 12 and $60 \%$ in this population [4]. Furthermore, cancer-associated cachexia has been indicated as the pivotal cause of CRC-related deaths, responsible for $22 \%$ thereof [5].

Trifluridine and tipiracil hydrochloride (TT) is a combination of a thymidine-based nucleoside analogue, trifluridine and a thymidine phosphorylase inhibitor, tipiracil. The efficacy and safety of TT in patients with metastatic CRC refractory or intolerance to standard therapies were evaluated in the phase III RECOURSE trial [6]. TT is one of the two drugs whose effectiveness has been confirmed in randomized trials. A number of other conventional chemotherapeutic agents, such as capecitabine, mitomycin $C$ and gemcitabine, are used as salvage therapy in CRC, but their beneficial effects in the third- or later-line setting are limited or doubtful. In some patients, retreatment with oxaliplatin or anti-EGFR rechallenge therapy might be an option [7]. Based on this background, TT and regorafenib have been established as standard treatments.

The aim of this study was to assess the incidence of sarcopenia in heavily pretreated metastatic CRC patients treated with TT chemotherapy, and the impact of skeletal muscle loss (SML) on progression-free survival (PFS) and overall survival (OS).

\section{Materials and Methods}

\subsection{Patients}

We retrospectively analyzed 78 patients from six cancer centres in Poland. The main inclusion criteria were as follows: histologically confirmed metastatic or locally advanced, previously treated colorectal cancer; Eastern Cooperative Oncology Group (ECOG) PS of 0, 1 or 2; at least one completed course of TT chemotherapy and availability of the computed tomography (CT) scans acquired as the baseline for the TT treatment (CT1) and as the first control during chemotherapy (CT2), evaluable for the skeletal muscle index (SMI) measurement. The baseline patient characteristics are presented in Table 1. Median age was 64.5 years (30-79), the male/female ratio was $43 / 35$, the colon/rectal cancer ratio was $50 / 28$ and ECOG PS of $0-1 / 2$ was $73 / 5$. All subjects were Caucasian. Prior disease progression during treatment with fluorouracil, oxaliplatin or irinotecan or anti-VEGF therapy and/or anti-EGFR therapy (in case of RAS wild-type status) was a prerequisite before the initiation of the TT treatment. TT was administered at $35 \mathrm{mg} / \mathrm{m}^{2}$ of body surface area for 5 days a week (with a 2-day rest) for 2 weeks, followed by a 14-day rest period, which completed each treatment cycle. The course was repeated every 4 weeks. The study was approved by the decision \#18/2019/VII of the Warmian-Masurian Medical Chamber Ethics Committee in Olsztyn (Poland).

Table 1. Patient characteristics.

\begin{tabular}{lccc}
\hline & Characteristics & $n$ & $\%$ \\
\hline Enrolled & & 78 & 100 \\
\hline Sex & Male & 43 & 55 \\
\hline & Female & 35 & 45 \\
\hline Age, years median (range) & & $64(30-78)$ \\
\hline
\end{tabular}


Table 1. Cont.

\begin{tabular}{|c|c|c|}
\hline Characteristics & $n$ & $\%$ \\
\hline \multicolumn{3}{|l|}{ ECOG performance status } \\
\hline 0 & 22 & 28 \\
\hline 1 & 51 & 65 \\
\hline 2 & 5 & 6 \\
\hline \multicolumn{3}{|l|}{ Primary site } \\
\hline Cecum & 7 & 9 \\
\hline Ascending colon & 4 & 5 \\
\hline Hepatic flexure of the large intestine & 3 & 4 \\
\hline Transverse colon & 4 & 5 \\
\hline Splenic flexure of the large intestine & 4 & 5 \\
\hline Colon descending & 3 & 4 \\
\hline Sigmoid & 17 & 22 \\
\hline Rectosigmoid junction & 8 & 10 \\
\hline Rectum & 28 & 36 \\
\hline \multicolumn{3}{|l|}{ Primary tumor location } \\
\hline Right colon & 17 & 22 \\
\hline Left colon & 61 & 78 \\
\hline \multicolumn{3}{|l|}{ Primary tumor histological subtype } \\
\hline Adenocarcinoma & 73 & 94 \\
\hline Mucinous adenocarcinoma & 4 & 5 \\
\hline Signet ring cell carcinoma & 1 & 1 \\
\hline \multicolumn{3}{|l|}{ Histological differentiation: } \\
\hline Well & 10 & 13 \\
\hline Moderate & 51 & 65 \\
\hline Poorly & 6 & 8 \\
\hline Unknown & 11 & 14 \\
\hline \multicolumn{3}{|l|}{ pT category } \\
\hline pT1 & 1 & 1 \\
\hline pT2 & 7 & 9 \\
\hline pT3 & 48 & 62 \\
\hline pT4 & 17 & 22 \\
\hline Not operated on & 5 & 6 \\
\hline \multicolumn{3}{|l|}{$\mathrm{pN}$ category } \\
\hline pN0 & 18 & 23 \\
\hline $\mathrm{pN} 1$ & 28 & 36 \\
\hline $\mathrm{pN} 2$ & 27 & 35 \\
\hline not operated on & 5 & 6 \\
\hline \multicolumn{3}{|l|}{ Site of metastasis } \\
\hline Liver & 49 & 63 \\
\hline Lung & 19 & 24 \\
\hline Lymph node & 18 & 23 \\
\hline Peritoneum & 16 & 21 \\
\hline \multicolumn{3}{|l|}{ KRAS mutation status } \\
\hline Wild-type & 36 & 46 \\
\hline Mutant & 40 & 51 \\
\hline \multicolumn{3}{|l|}{$B R A F$ mutation status } \\
\hline Wild-type & 61 & 78 \\
\hline Mutant & 6 & 7 \\
\hline \multicolumn{3}{|l|}{ NRAS mutation status } \\
\hline Wild-type & 72 & 92 \\
\hline Mutant & 1 & 1 \\
\hline
\end{tabular}

Abbreviation: ECOG Eastern Cooperative Oncology Group; pT: size or direct extent of the primary tumor given by histopathologic examination of a surgical specimen according to TNM staging system; pN: degree of spread to regional lymph nodes given by histopathologic examination of a surgical specimen. 


\subsection{Image Analysis}

Imaging-based sarcopenia assessment was carried out by an experienced radiologist using dedicated automatic software: DAFS (Data Analysis Facilitation Suite) ver. 2.0.5 (Voronoi Health Analytics, Vancouver, Canada) with the ABACS (Automatic Body composition Analyzer using Computed tomography image Segmentation) module provided by Voronoi Health Analytics, Canada (2020). Some non-optimal segmentations were re-edited using open-source software 3D Slicer ver. 4.11 (3D Slicer, Boston, Massachusetts, USA). As the third lumbar vertebra (L3) has long been established as a standard landmark, two consecutive CT images, extending at least from L3 to the iliac crest, were chosen to measure the muscle cross-sectional area. Skeletal muscles were identified and quantified based on Hounsfield Unit (HU) thresholds. All the selected CT scans were contrast-enhanced in the venous phase. The L3 region contains psoas, paraspinal and abdominal wall muscles. The L3 SMI was determined as a ratio of the skeletal muscle area $\left(\mathrm{SMA} ; \mathrm{cm}^{2}\right)$, contoured at the level of the L3 CT scan, to the patient's height squared $\left(\mathrm{m}^{2}\right)[8,9]$. An example of this procedure is presented at Figure 1.

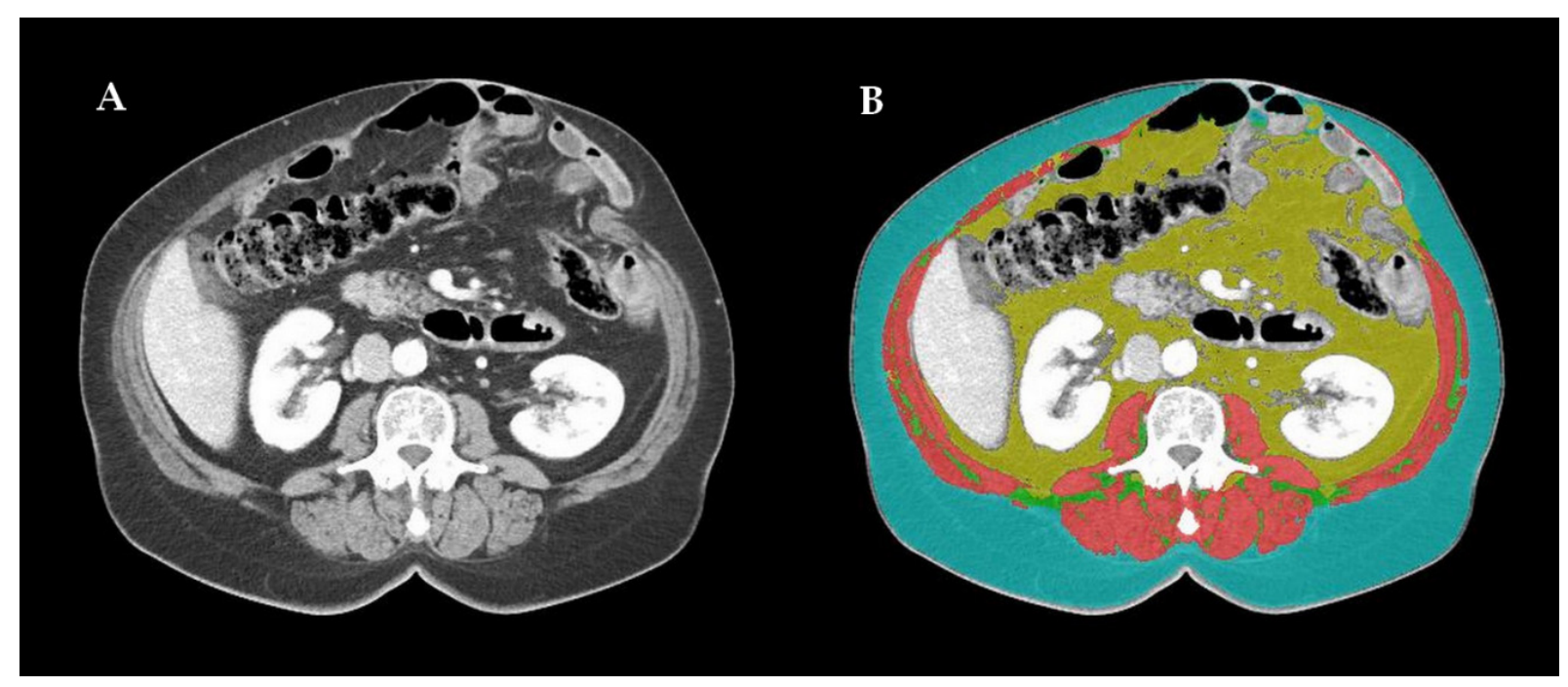

Figure 1. (A) Example of contrast-enhanced computed tomography scan of the third lumbar vertebra (L3) region in the venous phase (contains psoas, paraspinal and abdominal wall muscles); (B) image processed by Data Analysis Facilitation Suite ver. 2.0.5 by Voronoi Health Analytics, Vancouver, Canada with the Automatic Body composition Analyzer using Computed tomography image Segmentation module provided by Voronoi Health Analytics, Canada (2020); non-optimal segmentations were re-edited using open-source software 3D Slicer ver. 4.11 by 3D Slicer, Boston, MA, USA; skeletal muscles (pink) are separated from intra-abdominal fat (yellow) and subcutaneous fatty tissue (blue).

\subsection{Parameters and Statistical Analysis}

The L3 SMI below the 5th percentile was chosen as equivalent to sarcopenia, and the sarcopenia cut-off values of $52.4 \mathrm{~cm}^{2} / \mathrm{m}^{2}$ for men and $38.5 \mathrm{~cm}^{2} / \mathrm{m}^{2}$ for women were used for the study population analysis [9]. The predictive and prognostic value of the baseline sarcopenia and subsequent SML (at least 5\% decrease in SMI compared to baseline) were analyzed. Progression-free survival (PFS) was calculated from the date of treatment initiation to the date of disease progression defined by the RECIST 1.1 criteria or the date of the last follow-up. Overall survival (OS) was calculated from the date of treatment initiation to the date of death or the final follow-up date. The cut-off date for our analysis was set on 30 November 2020. Univariate analyzes of variables influencing PFS or OS were performed by log-rank test; this identified a preliminary list of significant factors. All the variables found significant or showing a trend towards significance $(p<0.1)$ in the univariate analysis were included in the multivariate analysis. The multivariate analysis of progression-free survival and overall survival were performed by Cox proportional 
hazards regression model using the forward stepwise method. Medians and life tables were computed using the product-limit estimate by the Kaplan and Meier method, and the log-rank test was employed to assess the statistical significance; $p$-values less than 0.05 were considered to indicate statistical significance. The statistical package MedCalc (ver. 19.7.2; MedCalc Software Ltd., Ostend, Belgium) was used for the analysis.

\section{Results}

\subsection{Patient Characteristics}

Of the initial cohort of 100 patients treated with TT, 78 were eligible for the final analysis; 22 patients were ineligible for lack of CT control or CT without contrast. Patients were enrolled from February 2017 to July 2020. The data cut-off was November 2020. The median observation period was 19.1 months (95\% CI, $11.2-19.3)$, and $66.7 \%$ of patients $(52 / 78)$ had died by the end of follow-up. The average interval between baseline and CT control was 104 days (48-323).

The median SMI, regardless of sex, at CT1 and CT2 was $47.89 \mathrm{~cm}^{2} / \mathrm{m}^{2}(27.68-71.95)$ and $46.43 \mathrm{~cm}^{2} / \mathrm{m}^{2}$ (25.94-70.64), respectively. Based on the assumed SMI thresholds, 34 patients were sarcopenic and 44 were non-sarcopenic at baseline; thus, sarcopenia was initially present in $44 \%$ of patients. In both groups the majority of patients did not demonstrate significant $(>5 \%$ ) SMI changes in the follow-up CT, but SMI decrease was more frequent than SMI increase on treatment. Sarcopenia has been reported in $47 \%$ of patients at the time of control.

\subsection{Efficacy}

Responses to chemotherapy are presented in Table 2. The Clinical Benefit Rate (CBR) in patients was $47.4 \%$ based on the RECIST v.1.1 criteria. Over half of patients (52.6\%) did not benefit from the treatment. The median PFS for the entire cohort was 3.6 months (95\% CI, 3.03-5.1; Figure 2A).

Table 2. Response in patients by RECIST v.1.1 criteria $(n=78)$.

\begin{tabular}{lcc}
\hline $\begin{array}{c}\text { Tumor Response by RECIST } \\
\text { v. 1.1 Criteria }\end{array}$ & $n$ & $\%$ \\
\hline CR & 0 & 0 \\
PR & 4 & 5.1 \\
SD & 33 & 42.3 \\
PD & 41 & 52.6 \\
CBR $=$ CR + PR + SD & 37 & 47.4 \\
\hline
\end{tabular}

Abbreviations: CR: complete response; PR: partial response; SD: stable disease; PD: progressive disease; CBR: clinical benefit rate.

A

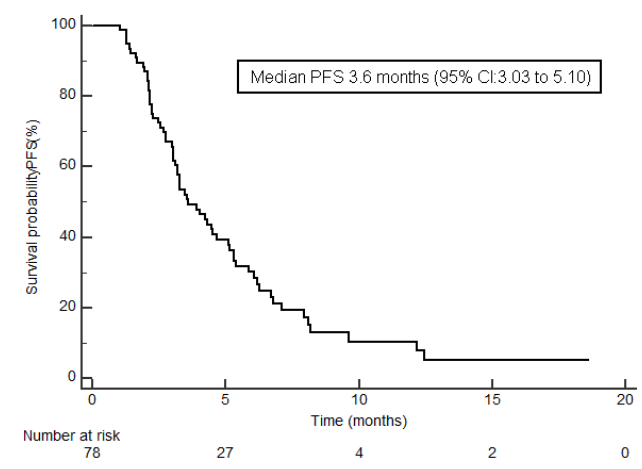

B

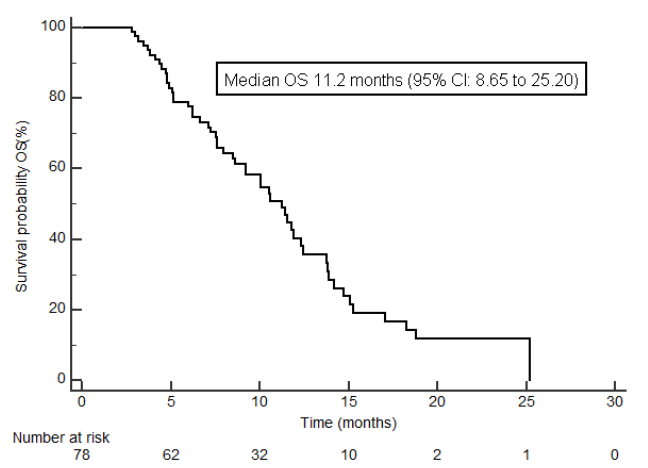

Figure 2. Kaplan-Meier curves showing (A) progression-free survival under trifluridine/tipiracil; (B) overall survival under trifluridine/tipiracil. 
Using the univariate analysis, we found the predictive significance of both baseline SMI and CEA serum level for PFS ( $p=0.0443$ and $p=0.0001$, respectively) (Figure 3A,B). In the multivariate analysis, we established that an unfavourable independent predictor for TT treatment was high CEA level (>5 ng/L) at baseline (HR: 5.11 (95\% CI, 1.56-16.71, $p=0.0070)$ ). The results of both univariate and multivariate analyzes of PFS are presented in Tables 3 and 4.

A

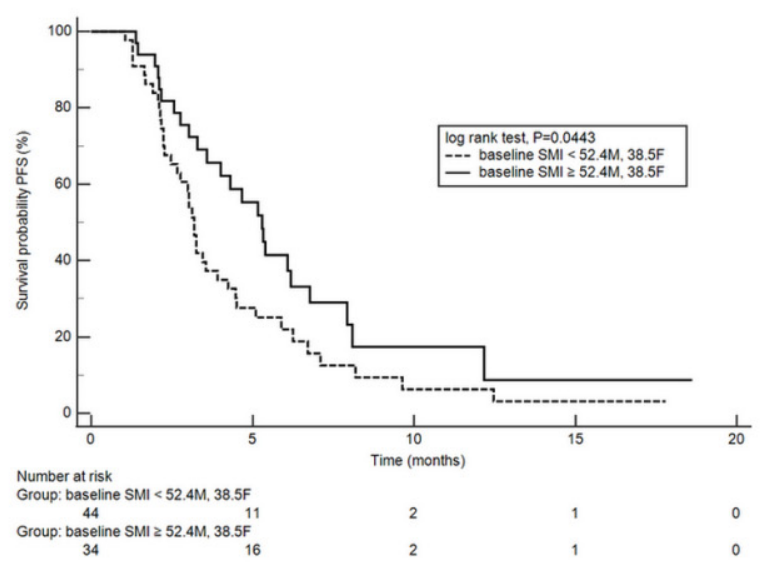

B

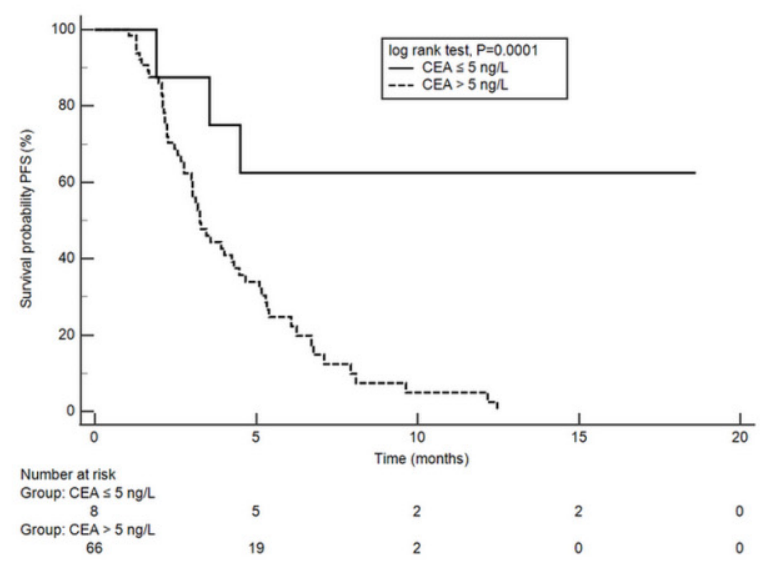

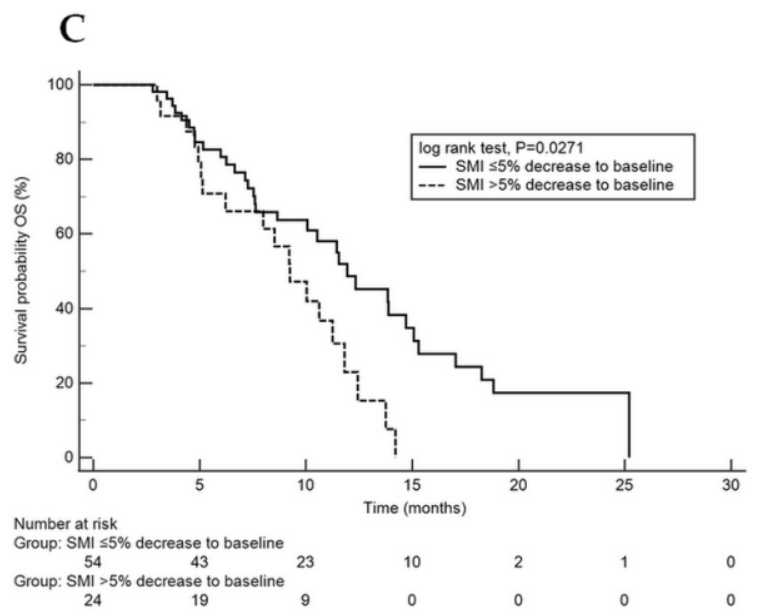

Figure 3. (A,B): Kaplan-Meier curves (KMC) showing progression-free survival under trifluridine/tipiracil. (A): KMC adjusted to baseline sarcopenia (yes or no); (B): KMC adjusted to carcinoembryonic antigen (normal or elevated); (C): KMC showing overall survival under trifluridine/tipiracil adjusted to SMI significant decrease on treatment (yes or no).

Table 3. Univariate analysis of progression free survival (log-rank test).

\begin{tabular}{cccc}
\hline Covariate & $\boldsymbol{n ( \% )}$ & Median (Months) & $\boldsymbol{p}$ Value \\
\hline Age & & & \\
$\leq 70$ year & $57(73 \%)$ & 3.9 & 0.9280 \\
$>70$ year & $21(27 \%)$ & 3.3 & \\
\hline Gender & & & \\
Male & $43(55 \%)$ & 3.5 & \\
Female & $35(45 \%)$ & 3.9 & 0.6813 \\
\hline Performance status & & & \\
(EGOG) & & 3.6 & \\
$0-1$ & $73(94 \%)$ & 3.5 & \\
2 & $5(6 \%)$ & &
\end{tabular}


Table 3. Cont.

\begin{tabular}{|c|c|c|c|}
\hline Covariate & $n(\%)$ & Median (Months) & $p$ Value \\
\hline \multicolumn{4}{|l|}{ Sites of metastases: } \\
\hline Liver & $49(63 \%)$ & 3.3 & \multirow{2}{*}{0.0936} \\
\hline Other & $29(37 \%)$ & 4.5 & \\
\hline \multicolumn{4}{|l|}{ Sites of metastases } \\
\hline Lymph nodes & $18(23 \%)$ & 3.6 & \multirow{2}{*}{0.6377} \\
\hline Other & $60(77 \%)$ & 3.3 & \\
\hline \multicolumn{4}{|l|}{ Sites of metastases: } \\
\hline Lung & $19(24 \%)$ & 3.0 & \multirow[t]{2}{*}{0.4293} \\
\hline Other & $59(76 \%)$ & 4.0 & \\
\hline \multicolumn{4}{|l|}{ Primary tumor: } \\
\hline left & $61(78 \%)$ & 3.4 & \multirow[t]{2}{*}{0.2698} \\
\hline rigth & $17(22 \%)$ & 4.3 & \\
\hline \multicolumn{4}{|l|}{ Histological differentiation: } \\
\hline Well/moderate & $61(78 \%)$ & 4.0 & \multirow[t]{2}{*}{0.1615} \\
\hline Poorly/unknown & $17(22 \%)$ & 3.0 & \\
\hline \multicolumn{4}{|l|}{ KRAS } \\
\hline Wild-type & $36(46 \%)$ & 4.2 & \multirow[t]{2}{*}{0.1798} \\
\hline Mutated & $40(51 \%)$ & 3.2 & \\
\hline \multicolumn{4}{|l|}{ NRAS } \\
\hline Wild-type & $72(92)$ & 3.6 & \multirow[t]{2}{*}{0.8595} \\
\hline mutated & $1(1)$ & 4.5 & \\
\hline \multicolumn{4}{|l|}{ BRAF } \\
\hline Wild-type & $61(78 \%)$ & 3.5 & \multirow[t]{2}{*}{0.8155} \\
\hline mutated & $6(7 \%)$ & 2.8 & \\
\hline \multirow{2}{*}{$\begin{array}{c}\text { baseline } \mathrm{SMI} \geq 52.4 \mathrm{M}, \\
38.5 \mathrm{~F} \\
\text { baseline } \mathrm{SMI}<52.4 \mathrm{M}, 38.5 \mathrm{~F}\end{array}$} & $34(44 \%)$ & 5.3 & \multirow{2}{*}{0.0443 * } \\
\hline & $44(56 \%)$ & 3.2 & \\
\hline \multirow{2}{*}{$\begin{array}{c}\mathrm{SMI} \leq 5 \% \text { decrease to } \\
\text { baseline } \\
\mathrm{SMI}>5 \% \text { decrease to } \\
\text { baseline }\end{array}$} & $54(69 \%)$ & 4.0 & \multirow[t]{2}{*}{0.1092} \\
\hline & $24(31 \%)$ & 3.3 & \\
\hline \multicolumn{4}{|l|}{ CEA } \\
\hline$>5 \mathrm{ng} / \mathrm{L}$ & $66(85 \%)$ & 3.3 & \multirow[t]{2}{*}{0.0001 * } \\
\hline$\leq 5 \mathrm{ng} / \mathrm{L}$ & $8(10 \%)$ & NR & \\
\hline
\end{tabular}

Abbreviations: ECOG: Eastern Cooperative Oncology Group, M-male; F-female; SMI—skeletal muscle index; CEA—carcinoembryonic antigen; * statistically significant $(p<0.05)$; NS—not significant; NR—not reached.

Table 4. Multivariate analysis of progression free survival.

\begin{tabular}{lcccc}
\hline \multicolumn{1}{c}{ Parameter } & $p$ & HR & HR 95\% Lower & HR 95\% Upper \\
\hline CEA: $>5$ ng $/$ L vs. $\leq 5 \mathrm{ng} / \mathrm{L}$ & 0.0070 & 5.11 & 1.56 & 16.71 \\
\hline KRAS: Mutated vs. Wild-type & 0.1883 & 1.41 & 0.84 & 2.36 \\
\hline $\begin{array}{l}\text { baseline SMI: } \geq 52.4 \mathrm{M}, 38.5 \mathrm{~F} \text { vs. } \\
<52.4 \mathrm{M}, 38.5 \mathrm{~F}\end{array}$ & 0.1362 & 0.68 & 0.40 & 1.13
\end{tabular}

Abbreviations: M-male; F-Female; SMI—skeletal muscle index; CEA—carcinoembryonic antigen; HR—hazard ratio; NS-not significant.

The median OS for the study population was 11.2 months (95\% CI, 8.65-25.20; Figure 2B). The results of the univariate analysis of overall survival indicate that baseline sarcopenia was not associated with poor outcomes in the study cohort $(p=0.3963)$. However, the univariate (Figure $3 \mathrm{C}$ ) and multivariate analyzes of overall survival revealed that both a $>5 \%$ decrease in SMI between CT1 and CT2 and poor or unknown histological 
differentiation achieved the significance levels for predictive factors for reduced survival [HR: 2.03 (1.11-3.72), $p=0.0039$ and HR: 2.34 (95\% CI 1.17-4.66), $p=0.0159$, respectively; Tables 5 and 6.

Table 5. Univariate analysis of overall survival (log-rank test).

\begin{tabular}{|c|c|c|c|}
\hline Covariate & $n(\%)$ & Median (Months) & $p$ Value \\
\hline \multicolumn{4}{|l|}{ Age } \\
\hline$\leq 70$ year & $57(73 \%)$ & 11.4 & \multirow[t]{2}{*}{0.1875} \\
\hline$>70$ year & $21(27 \%)$ & 7.3 & \\
\hline \multicolumn{4}{|l|}{ Gender } \\
\hline Male & $43(55 \%)$ & 11.2 & \multirow[t]{2}{*}{0.9625} \\
\hline Female & $35(45 \%)$ & 9.6 & \\
\hline \multicolumn{4}{|l|}{ Performance status (EGOG) } \\
\hline $0-1$ & $73(94 \%)$ & 10.6 & \multirow[t]{2}{*}{0.5605} \\
\hline 2 & $5(6 \%)$ & 11.4 & \\
\hline \multicolumn{4}{|l|}{ Sites of metastases: } \\
\hline Liver & $49(63 \%)$ & 10.2 & \multirow[t]{2}{*}{0.1823} \\
\hline Other & $29(37 \%)$ & 11.9 & \\
\hline \multicolumn{4}{|l|}{ Sites of metastases } \\
\hline Lymph nodes & $18(23 \%)$ & 9.2 & \multirow[t]{2}{*}{0.4159} \\
\hline Other & $60(77 \%)$ & 10.8 & \\
\hline \multicolumn{4}{|l|}{ Sites of metastases: } \\
\hline Lung & $19(24 \%)$ & 13.7 & \multirow[t]{2}{*}{0.2640} \\
\hline Other & $59(76 \%)$ & 10.5 & \\
\hline \multicolumn{4}{|l|}{ Primary tumor: } \\
\hline Left & $61(78 \%)$ & 11.2 & \multirow[t]{2}{*}{0.2598} \\
\hline Right & $17(22 \%)$ & 7.6 & \\
\hline \multicolumn{4}{|l|}{ Histological differentiation: } \\
\hline Well/moderate & $61(78 \%)$ & 11.5 & \multirow[t]{2}{*}{0.0428} \\
\hline Poorly/unknown & $17(22 \%)$ & 8.6 & \\
\hline \multicolumn{4}{|l|}{ KRAS } \\
\hline Wild type & $36(46 \%)$ & 10.5 & \multirow[t]{2}{*}{0.6737} \\
\hline Mutated & $40(51 \%)$ & 10.6 & \\
\hline \multicolumn{4}{|l|}{ NRAS } \\
\hline Wild type & $72(92)$ & 10.5 & \multirow[t]{2}{*}{0.4727} \\
\hline Mutated & $1(1)$ & 9.5 & \\
\hline \multicolumn{4}{|l|}{ BRAF } \\
\hline Wild type & $61(78 \%)$ & 10.6 & \multirow[t]{2}{*}{0.1235} \\
\hline Mutated & $6(7 \%)$ & 7.3 & \\
\hline $\mathrm{SMI} \geq$ baseline $52.4 \mathrm{M}, 38.5 \mathrm{~F}$ & $34(44 \%)$ & 11.1 & \multirow{2}{*}{0.6823} \\
\hline SMI $<$ baseline $52.4 \mathrm{M}, 38.5 \mathrm{~F}$ & $44(56 \%)$ & 10.0 & \\
\hline $\mathrm{SMI} \leq 5 \%$ decrease to baseline & $54(69 \%)$ & 11.8 & \multirow{2}{*}{0.0271 * } \\
\hline SMI $>5 \%$ decrease to baseline & $24(31 \%)$ & 9.2 & \\
\hline \multicolumn{4}{|l|}{ CEA } \\
\hline$>5 \mathrm{ng} / \mathrm{L}$ & $66(85 \%)$ & 10.2 & 0.0300 \\
\hline$\leq 5 \mathrm{ng} / \mathrm{L}$ & $8(10 \%)$ & NR & \\
\hline
\end{tabular}


Table 6. Multivariate analysis of overall survival.

\begin{tabular}{lcccc}
\hline \multicolumn{1}{c}{ Parameter } & $p$ & HR & HR 95\% Lower & HR 95\% Upper \\
\hline $\begin{array}{l}\text { Histological differentiation: well/ } \\
\text { moderate vs. poorly / unknown }\end{array}$ & 0.0159 & 2.34 & 1.17 & 4.66 \\
\hline $\begin{array}{l}\text { SMI: } \leq 5 \% \text { vs. }>5 \% \text { decrease } \\
\text { to baseline }\end{array}$ & 0.0039 & 2.03 & 1.11 & 3.72 \\
\hline CEA: $>5 \mathrm{ng} / \mathrm{L}$ vs. $\leq 5 \mathrm{ng} / \mathrm{L}$ & 0.0959 & 3.29 & 0.81 & 13.34 \\
\hline
\end{tabular}

Abbreviations: M-male; F-female; SMI—skeletal muscle index; CEA—Carcinoembryonic antigen; HR—hazard ratio.

\subsection{Toxicity}

Treatment-related adverse events, according to the National Cancer Institute Common Terminology Criteria for Adverse Events ver. 4.03, occurred in 77 patients $(99 \%)$, while adverse events of grade 3 or higher occurred in 51 patients (65\%; Table 7). The most frequent treatment toxicities were anemia $(82 \%)$, neutropenia $(69 \%)$, fatigue $(67 \%)$, decreased appetite (45\%) and weight loss (40\%; Table 7$)$. In the study group, $13 \%$ of patients required dose reductions, and $94 \%$ required dose delay due to drug-related adverse events. No fatal adverse events were reported.

Table 7. Frequency of Adverse Events.

\begin{tabular}{|c|c|c|c|c|c|c|}
\hline \multirow[b]{3}{*}{ Event } & \multirow{2}{*}{\multicolumn{2}{|c|}{$\begin{array}{l}\text { Entire Study Population } \\
\qquad(n=78)\end{array}$}} & \multicolumn{4}{|c|}{ Frequency of Toxicities by SML } \\
\hline & & & \multicolumn{2}{|c|}{$\begin{array}{c}\text { SMI } \leq 5 \% \text { Decrease to Baseline } \\
(n=54)\end{array}$} & \multicolumn{2}{|c|}{$\begin{array}{c}\text { SMI > 5\% Decrease to Baseline } \\
(n=24)\end{array}$} \\
\hline & Any Grade & Grade $\geq 3$ & Any Grade & Grade $\geq 3$ & Any Grade & Grade $\geq 3$ \\
\hline Any event-no. (\%) & $77(99)$ & $51(65)$ & $54(100)$ & $39(72)$ & $23(96)$ & $12(50)$ \\
\hline Stomatitis-no. (\%) & $6(8)$ & 0 & $3(6)$ & 0 & $3(13)$ & 0 \\
\hline Hand-foot syndrome-no. (\%) & 0 & 0 & 0 & 0 & 0 & 0 \\
\hline Skin lesions-no. (\%) & $4(5)$ & 0 & $3(6)$ & 0 & $1(4)$ & 0 \\
\hline Diarrhea-no. (\%) & $19(24)$ & $1(1)$ & $16(30)$ & $1(1)$ & $3(13)$ & 0 \\
\hline Pneumonia-no. (\%) & $5(6)$ & 0 & $5(9)$ & 0 & 0 & 0 \\
\hline Nausea-no. (\%) & $16(21)$ & $2(3)$ & $9(17)$ & 0 & $7(29)$ & $2(8)$ \\
\hline Vomiting-no. (\%) & $8(10)$ & $2(3)$ & $3(6)$ & 0 & $5(21)$ & $2(8)$ \\
\hline Anemia-no. (\%) & $64(82)$ & $15(19)$ & $43(80)$ & $9(17)$ & $21(88)$ & $6(25)$ \\
\hline Neutropenia-no. (\%) & $54(69)$ & $36(46)$ & $39(72)$ & $30(56)$ & $15(63)$ & $6(25)$ \\
\hline Lymphopenia-no. (\%) & $30(38)$ & $4(5)$ & $21(39)$ & $3(6)$ & $9(38)$ & $1(4)$ \\
\hline Thrombocytopenia-no. (\%) & $15(19)$ & $3(4)$ & $10(19)$ & $2(4)$ & $5(21)$ & $1(4)$ \\
\hline ALT increased-no. $(\%)$ & $27(35)$ & $2(3)$ & $18(33)$ & $1(1)$ & $9(38)$ & $1(4)$ \\
\hline AST increased-no. (\%) & $23(29)$ & $2(3)$ & $19(35)$ & $1(1)$ & $4(17)$ & $1(4)$ \\
\hline Fatigue-no. (\%) & $52(67)$ & $8(9)$ & $35(65)$ & $4(7)$ & $17(71)$ & $4(4)$ \\
\hline Decreased appetite-no. (\%) & $35(45)$ & $2(3)$ & $22(41)$ & 0 & $13(54)$ & $2(8)$ \\
\hline Constipation-no. (\%) & $8(10)$ & 0 & $6(11)$ & 0 & $2(8)$ & 0 \\
\hline Weight loss-no. (\%) & $31(40)$ & 0 & $17(31)$ & 0 & $14(58)$ & 0 \\
\hline
\end{tabular}

\section{Discussion}

Although sarcopenia has previously been associated with poor prognosis in colorectal cancer, most studies conducted to date have addressed the entire CRC population regardless of the disease advancement or previous treatment. We investigated the association between sarcopenia and PFS/OS in advanced CRC patients treated with TT.

In our study, we identified the unfavourable predictive role of both baseline SMI $\left(<52.4 \mathrm{~cm}^{2} / \mathrm{m}^{2}\right.$ for men and $<38.5 \mathrm{~cm}^{2} / \mathrm{m}^{2}$ for women) and CEA serum level ( $\left.>5 \mathrm{ng} / \mathrm{L}\right)$ for 
the TT therapy. Although baseline sarcopenia was not associated with poor outcomes in the study cohort, both a $>5 \%$ decrease in SMI between CT1 and CT2 and poor or unknown histological differentiation had a negative impact on survival.

It is noteworthy that the median PFS for the entire cohort (3.6 months) was higher than in the TT pivotal trial RECOURSE (2.0 months) or the majority of real-world studies [10]. Furthermore, the median OS for the study population (11.2 months) was also significantly higher than in the RECOURSE trial (7.1 months) or other available real-world studies.

A sarcopenia diagnosis is confirmed by the presence of low muscle quantity or quality. Three parameters need to be measured: muscle strength, muscle quantity and physical performance. Total body fat-free mass (FFM) is considered a more effective diagnostic indicator for cancer cachexia than body mass index (BMI), which can be false negative among patients with sarcopenic obesity. Apparently, muscle mass loss is common in cancer patients and does not only occur in underweight individuals. Weight loss has already been associated with reduced median survival [11]. Several hormonal and immunologic factors have been linked to the possible pathophysiological mechanism of muscle atrophy; these include nerve growth factor (NGF), growth hormone, androgens/estrogens deficiency, abnormalities in protein and amino acid metabolism, and inflammatory cytokines (IL-1 $\beta$, TNF- $\alpha$ and IL-6) or overproduction of parathyroid hormone-related protein $[12,13]$.

To date, there have been only two small retrospective studies investigating the role of the FFM loss in metastatic colorectal cancer treated with TT (or regorafenib). According to a retrospective analysis by Huemer et al., treatment with regorafenib was associated with a statistically significant skeletal muscle loss in later-line treatment, which was not the case with TT. However, subclassification of patients into three groups, namely normal muscle mass, stable sarcopenia and new-onset sarcopenia, at the initiation of third-line therapy permitted discrimination of overall survival, with 1-year overall survival rates of 61,29 and $16 \%$, respectively $(p=0.04)$ [14]. It is noteworthy that the skeletal muscle loss was significantly higher in patients treated with regorafenib in comparison to patients who received TT also in the sex- and age-adjusted multivariate analysis, as concluded by Hacioglu et al. [15].

Several studies have been published linking sarcopenia to poor outcomes in either non-metastatic or advanced CRC patients [16-21]. As mentioned before, the occurrence of baseline sarcopenia was rare in the study population, especially in women. Furthermore, a number of different patterns of 'metabolic' response were observed, as presented in Table 8, which implies that cancer-related sarcopenia and cachexia should be always considered a multifactorial phenomenon. It is estimated that only 40 and $20 \%$ of CRC patients initially treated for advanced disease worldwide are able to begin the thirdand fourth-line treatment, respectively [22]. Our study suggests the complex image of patients treated with oral chemotherapy after average 2.6 previous treatment regimens. Although this population typically does not benefit in terms of progression-free survival, paradoxically it seems to be more predestined for improved overall survival owing to particular 'immune resistance' that allows for responses to previous treatment regimens or better performance status in general. Conversely, in the first-line setting, SML at 3 months was associated with poor objective response rate (ORR; $p<0.01)$, and poor progression-free survival (PFS; $p=0.03)$, and it was an independent predictive factor for poor ORR $(p=0.01)$ and PFS ( $p=0.04)$ according to a study by Sasaki et al. [21]. 
Table 8. Patterns of 'metabolic' response.

\begin{tabular}{ccc}
\hline & $\begin{array}{c}\text { Normal SMI at Baseline } \\
n=\mathbf{4 4}(\mathbf{5 6} \%)\end{array}$ & $\begin{array}{c}\text { Sarcopenia at Baseline } \\
n=34 \mathbf{4 4 \% )}\end{array}$ \\
\hline $\begin{array}{c}\text { SMI 5\% decrease on treatment } \\
n=24(31 \%)\end{array}$ & $n=18(23 \%)$ & $n=6(8 \%)$ \\
\hline $\begin{array}{c}\text { No significant SMI changes } \\
n=48(62 \%)\end{array}$ & $n=23(29 \%)$ & $n=26(33 \%)$ \\
\hline $\begin{array}{c}\text { SMI 5\% increase on treatment } \\
n=6(7 \%)\end{array}$ & $n=3(4 \%)$ & $n=2(3 \%)$ \\
\hline
\end{tabular}

Abbreviations: SMI—skeletal muscle index.

The effect of sarcopenia on chemotherapy toxicity among metastatic CRC patients has been evaluated previously [4]. SML has been described as factor associated with chemotherapy grade 3-4 toxicities including severe nausea, vomiting, peripheral neuropathy, neutropenia and anemia. Significant number of patients in our study developed treatment toxicity including $65 \%$ of grade $3-4$ adverse events (Table 7 ). The majority of them were blood count disorders: anemia, neutropenia, lymphopenia, and thrombocytopenia, and could be considered multifactorial: both as a chemotherapy-induced toxicity and as cancer-related complications connected to sarcopenia. In Table 7, we also present differences of the frequency of toxicities by SML (SMI: $\leq 5 \%$ vs. $>5 \%$ decrease to baseline) which is comparable in both groups. In our study we did not investigate either correlation between SML and blood count disorders, nor the predictive value of neutropenia or lymphopenia. Available literature indicates association of sarcopenia with immune system functions as a valuable research direction.

A relatively small number of patients, CT images performed in six different institutions and multifactoriality of worse patient outcomes were major limitations to our study. Furthermore, in the present study we defined sarcopenia using sex-specific CT L3 SMI cut-offs of $52.4 \mathrm{~cm}^{2} / \mathrm{m}^{2}$ in men and $38.5 \mathrm{~cm}^{2} / \mathrm{m}^{2}$ in women according to Prado et al., while the fifth percentile was considered the cut-off point between low and normal [9]. However, cut-offs for CT L3 SMI vary in the literature, and this variety depends on differences in analyzed populations, such as age, racial structure, socioeconomic status or diseases present [23]. The additional analysis of two other sex-specific cut-offs available for similar population $[24,25]$ was also negative for mPFS and mOS. Moreover, the diagnosis of sarcopenia is more complex than muscle quantity measurement and needs to be confirmed with other parameters, including muscle strength and physical performance, which was not possible in our study due to its retrospective nature. Relatively higher survival results may be related to partially biased patient selection, resulting from the exclusion of subjects without objective response evaluation. Finally, another limitation was adverse event reporting in the source documentation, which was occasionally incomplete, mostly with respect to subjective toxicities, such as nausea or fatigue.

\section{Conclusions}

Sarcopenia is common in advanced CRC patients treated with TT and affects overall survival. CEA serum level before the treatment onset seems to be a significant predictive factor for TT response, but this needs to be confirmed in further studies. TT chemotherapy in third- or later-line should be personalized as far as practicable due to its relatively low effect and frequent adverse events. Determining the optimal drug sequence in later-line chemotherapy of CRC is a significant challenge due to a small number of patients eligible for studies, and searching for valuable predictive factors requires further research. 
Author Contributions: Conceptualization, L.B. and M.M. (Mateusz Malik); software, M.M. (Maciej Michalak); formal analysis, M.M. (Maciej Michalak) and L.B.; investigation, B.R., M.G., A.J., K.H., B.K.-Z., M.O., H.R.-D. and M.M. (Mateusz Malik); data curation, M.M. (Mateusz Malik); writingoriginal draft preparation, M.M. (Mateusz Malik); writing-review and editing, L.B.; visualization, M.M. (Mateusz Malik); supervision, E.F.-C., B.R., M.F.-K., D.M. and L.B. All authors have read and agreed to the published version of the manuscript.

Funding: The APC was funded by Servier Polska.

Institutional Review Board Statement: The study was conducted according to the guidelines of the Declaration of Helsinki, and approved by the Warmian-Masurian Medical Chamber Ethics Committee in Olsztyn, Poland (the decision \#18/2019/VII).

Informed Consent Statement: Patient consent was waived due to the retrospective nature of the study.

Data Availability Statement: The data that support the findings of this study are available from the corresponding author, upon reasonable request.

Conflicts of Interest: M. Malik: Travel/Accommodation/Expenses: Servier, Bristol-Myers Squibb. M. Gełej: Honoraria (self): Servier; B. Kania-Zembaczyńska: Honoraria (self): Servier, Amgen, Merck. L. Bodnar: Advisory/Consultancy: GSK Commercial Sp z o.o, Speaker Bureau/Expert testimony: Roche, Ipsen, Amgen; Travel/Accommodation/Expenses: Servier. All other authors have declared no conflicts of interest.

\section{References}

1. Mattiuzzi, C.; Sanchis-Gomar, F.; Lippi, G. Concise Update on Colorectal Cancer Epidemiology. Ann. Transl. Med. 2019, 7, 609. [CrossRef]

2. Krzakowski, M.; Potemski, P.; Warzocha, K.; Wysocki, P. Onkologia Kliniczna; Via Medica: Gdańsk, Poland, 2015; ISBN 978-837599-796-5.

3. Cruz-Jentoft, A.J.; Bahat, G.; Bauer, J.; Boirie, Y.; Bruyère, O.; Cederholm, T.; Cooper, C.; Landi, F.; Rolland, Y.; Sayer, A.A.; et al. Sarcopenia: Revised European Consensus on Definition and Diagnosis. Age Aging 2019, 48, 16-31. [CrossRef] [PubMed]

4. Vergara-Fernandez, O.; Trejo-Avila, M.; Salgado-Nesme, N. Sarcopenia in Patients with Colorectal Cancer: A Comprehensive Review. World J. Clin. Cases 2020, 8, 1188-1202. [CrossRef]

5. Warren, S. The Immediate Causes of Death in Cancer. Am. J. Med. Sci. 1932, 184, 610-615. [CrossRef]

6. Mayer, R.J.; Van Cutsem, E.; Falcone, A.; Yoshino, T.; Garcia-Carbonero, R.; Mizunuma, N.; Yamazaki, K.; Shimada, Y.; Tabernero, J.; Komatsu, Y.; et al. Randomized Trial of TAS-102 for Refractory Metastatic Colorectal Cancer. N. Engl. J. Med. 2015, 372, 1909-1919. [CrossRef] [PubMed]

7. Nielsen, D.L.; Palshof, J.A.; Larsen, F.O.; Jensen, B.V.; Pfeiffer, P. A Systematic Review of Salvage Therapy to Patients with Metastatic Colorectal Cancer Previously Treated with Fluorouracil, Oxaliplatin and Irinotecan +/ - Targeted Therapy. Cancer Treat. Rev. 2014, 40, 701-715. [CrossRef] [PubMed]

8. Gomez-Perez, S.L.; Haus, J.M.; Sheean, P.; Patel, B.; Mar, W.; Chaudhry, V.; McKeever, L.; Braunschweig, C. Measuring Abdominal Circumference and Skeletal Muscle from a Single Cross-Sectional Computed Tomography Image. J. Parenter. Enter. Nutr. 2016, 40, 308-318. [CrossRef]

9. Prado, C.M.M.; Lieffers, J.R.; McCargar, L.J.; Reiman, T.; Sawyer, M.B.; Martin, L.; Baracos, V.E. Prevalence and Clinical Implications of Sarcopenic Obesity in Patients with Solid Tumors of the Respiratory and Gastrointestinal Tracts: A PopulationBased Study. Lancet Oncol. 2008, 9, 629-635. [CrossRef]

10. Bekaii-Saab, T.; Kim, R.; Kim, T.W.; O'Connor, J.M.; Strickler, J.H.; Malka, D.; Sartore-Bianchi, A.; Bi, F.; Yamaguchi, K.; Yoshino, T.; et al. Third- or Later-Line Therapy for Metastatic Colorectal Cancer: Reviewing Best Practice. Clin. Colorectal Cancer 2019, 18, e117-e129. [CrossRef]

11. Dewys, W.D.; Begg, C.; Lavin, P.T.; Band, P.R.; Bennett, J.M.; Bertino, J.R.; Cohen, M.H.; Douglass, H.O.; Engstrom, P.F.; Ezdinli, E.Z.; et al. Prognostic Effect of Weight Loss Prior to Chemotherapy in Cancer Patients. Eastern Cooperative Oncology Group. Am. J. Med. 1980, 69, 491-497. [CrossRef]

12. Morley, J.E.; Baumgartner, R.N.; Roubenoff, R.; Mayer, J.; Nair, K.S. Sarcopenia. J. Lab. Clin. Med. 2001, 137, 231-243. [CrossRef] [PubMed]

13. Argilés, J.M.; Busquets, S.; Stemmler, B.; López-Soriano, F.J. Cancer Cachexia: Understanding the Molecular Basis. Nat. Rev. Cancer 2014, 14, 754-762. [CrossRef] [PubMed]

14. Huemer, F.; Schlintl, V.; Hecht, S.; Hackl, H.; Melchardt, T.; Rinnerthaler, G.; Greil, R.; Weiss, L. Regorafenib Is Associated with Increased Skeletal Muscle Loss Compared to TAS-102 in Metastatic Colorectal Cancer. Clin. Colorectal Cancer 2019, 18, $159-166 . e 3$. [CrossRef] [PubMed] 
15. Bekir Hacioglu, M.; Kostek, O.; Kurt, N.; Kucukarda, A.; Gokyer, A.; Ustabasioglu, F.E.; Karatas, F.; Tuncbilek, N.; Uzunoglu, S.; Bilici, A.; et al. Comparison of Skeletal Muscle Mass Loss in Patients with Metastatic Colorectal Cancer Treated with Regorafenib or TAS-102. J. BUON 2019, 24, 2198-2204. [PubMed]

16. Peng, P.D.; van Vledder, M.G.; Tsai, S.; de Jong, M.C.; Makary, M.; Ng, J.; Edil, B.H.; Wolfgang, C.L.; Schulick, R.D.; Choti, M.A.; et al. Sarcopenia Negatively Impacts Short-Term Outcomes in Patients Undergoing Hepatic Resection for Colorectal Liver Metastasis. HPB (Oxford) 2011, 13, 439-446. [CrossRef] [PubMed]

17. van Vledder, M.G.; Levolger, S.; Ayez, N.; Verhoef, C.; Tran, T.C.K.; Ijzermans, J.N.M. Body Composition and Outcome in Patients Undergoing Resection of Colorectal Liver Metastases. Br. J. Surg. 2012, 99, 550-557. [CrossRef]

18. Huang, D.-D.; Wang, S.-L.; Zhuang, C.-L.; Zheng, B.-S.; Lu, J.-X.; Chen, F.-F.; Zhou, C.-J.; Shen, X.; Yu, Z. Sarcopenia, as Defined by Low Muscle Mass, Strength and Physical Performance, Predicts Complications after Surgery for Colorectal Cancer. Colorectal Dis. 2015, 17, O256-O264. [CrossRef]

19. Kurk, S.A.; Peeters, P.H.M.; Dorresteijn, B.; de Jong, P.A.; Jourdan, M.; Kuijf, H.J.; Punt, C.J.A.; Koopman, M.; May, A.M. Impact of Different Palliative Systemic Treatments on Skeletal Muscle Mass in Metastatic Colorectal Cancer Patients. J. Cachexia Sarcopenia Muscle 2018, 9, 909-919. [CrossRef]

20. Vashi, P.G.; Gorsuch, K.; Wan, L.; Hill, D.; Block, C.; Gupta, D. Sarcopenia Supersedes Subjective Global Assessment as a Predictor of Survival in Colorectal Cancer. PLoS ONE 2019, 14, e0218761. [CrossRef]

21. Sasaki, S.; Oki, E.; Saeki, H.; Shimose, T.; Sakamoto, S.; Hu, Q.; Kudo, K.; Tsuda, Y.; Nakashima, Y.; Ando, K.; et al. Skeletal Muscle Loss during Systemic Chemotherapy for Colorectal Cancer Indicates Treatment Response: A Pooled Analysis of a Multicenter Clinical Trial (KSCC 1605-A). Int. J. Clin. Oncol. 2019, 24, 1204-1213. [CrossRef]

22. Carlomagno, C.; De Stefano, A.; Rosanova, M.; De Falco, S.; Attademo, L.; Fiore, G.; De Placido, S. Multiple Treatment Lines and Prognosis in Metastatic Colorectal Cancer Patients. Cancer Metastasis Rev. 2019, 38, 307-313. [CrossRef] [PubMed]

23. Walowski, C.O.; Braun, W.; Maisch, M.J.; Jensen, B.; Peine, S.; Norman, K.; Müller, M.J.; Bosy-Westphal, A. Reference Values for Skeletal Muscle Mass-Current Concepts and Methodological Considerations. Nutrients 2020, 12, 755. [CrossRef] [PubMed]

24. Derstine, B.A.; Holcombe, S.A.; Ross, B.E.; Wang, N.C.; Su, G.L.; Wang, S.C. Skeletal Muscle Cutoff Values for Sarcopenia Diagnosis Using T10 to L5 Measurements in a Healthy US Population. Sci. Rep. 2018, 8, 11369. [CrossRef] [PubMed]

25. van der Werf, A.; Langius, J.A.E.; de van der Schueren, M.A.E.; Nurmohamed, S.A.; van der Pant, K.A.M.I.; BlauwhoffBuskermolen, S.; Wierdsma, N.J. Percentiles for Skeletal Muscle Index, Area and Radiation Attenuation Based on Computed Tomography Imaging in a Healthy Caucasian Population. Eur. J. Clin. Nutr. 2018, 72, 288-296. [CrossRef] [PubMed] 